\title{
Astroblastoma - a rare and challenging tumor: a case report and review of the literature
}

\author{
Nawal Hammas ${ }^{1,2^{*}}$, Nadia Senhaji ${ }^{3}$, My Youssef Alaoui Lamrani ${ }^{4,5}$, Sanae Bennis ${ }^{2,6}$, Elfaiz Mohamed Chaoui ${ }^{5,7}$, \\ Hind El Fatemi ${ }^{1,2}$ and Laila Chbani ${ }^{1,2}$
}

\begin{abstract}
Background: Astroblastoma is a controversial and an extremely rare central nervous system neoplasm. Although its histogenesis has been clarified recently, controversies exist regarding its cellular origin and validity as a distinct entity. Because of its extreme rarity and because its common features are shared with other glial neoplasms, this tumor is prone to misdiagnosis and remains challenging not only in terms of diagnosis and classification but also in the subsequent management. This case report describes a new case of astroblastoma. It discusses clinical, radiologic, pathological, and therapeutic features and differential diagnosis of this rare neoplasm, with a review of the recent literature.

Case presentation: We report the case of an 8-year-old Moroccan girl who presented with a 1-year history of epileptic seizure, headache, and decreased visual acuity. Cranial magnetic resonance imaging revealed a right occipito-temporal mass. A tumor resection was performed and histological examination combined with immunohistochemical study confirmed the diagnosis of low-grade astroblastoma.

Conclusions: Astroblastoma is a very rare primary brain tumor. Its diagnosis is often challenging because of the astroblastic aspects that can be found in astrocytic tumors, in ependymomas, and in non-neuroepithelial tumors. Considerable confusion surrounds its histogenesis and classification. The low incidence rate makes it difficult to conduct studies to examine tumor characteristics.
\end{abstract}

Keywords: Astroblastoma, Brain neoplasm, Histogenesis, Immunohistochemistry, Differential diagnosis

\section{Background}

Astroblastoma is a controversial and an extremely rare central nervous system neoplasm [1-4]. It accounts for 0.45 to $2.8 \%$ of all neuroglial tumors and it is mainly located in the cerebral hemispheres of children, teenagers, and young adults [1, 2, 4-9]. It was initially described by Bailey and Cushing in 1926 [10] as a separate glial tumor and further characterized by Bailey and Bucy in 1930 [11]. Although its histogenesis has been clarified recently, controversies exist regarding its cellular origin and validity as a distinct entity, because it shares features of both astrocytomas and ependymomas $[1,5]$. In the

\footnotetext{
* Correspondence: nawalhammas@gmail.com

'Department of Pathology, Hassan II University Hospital, 30000 Fez, Morocco

${ }^{2}$ Biomedical and Translational Research Laboratory, Faculty of Medicine and

Pharmacy, Sidi Mohamed Ben Abdellah University, Fez, Morocco

Full list of author information is available at the end of the article
}

literature on brain tumor classification, this tumor has been categorized as follows: as a stage in the process of glioma dedifferentiation [12], as an astrocytoma of large cells producing fibers [13], or as a rare tumor, probably originating from tanycytes or ependymal astrocytes [14, 15]. Finally, it was listed among "other neuroepithelial tumors" in the WHO Classification of Tumours of the Central Nervous System [16]. Astroblastomas can be graded as either a low-grade or high-grade (anaplastic/ malignant) variant. This histopathologic subtyping was applied by many pathologists, but has not yet been integrated in the World Health Organization (WHO) classification [3, 17]. Because of its extreme rarity and because its radiologic and histopathologic features are common and shared with other glial neoplasms, this tumor is prone to misdiagnosis and remains challenging 


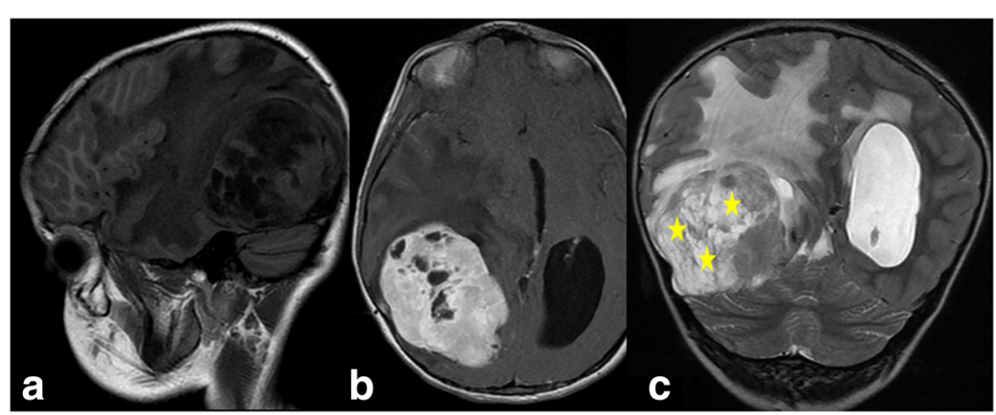

Fig. 1 Cranial magnetic resonance imaging revealed a right, occipito-temporal, voluminous, well-demarcated mass, hypointense heterogenous on T1-weighted images (a) with a strong contrast enhancement (b) and a characteristic multicystic bubbly appearance on T2-weighted images (c). There was a peritumoral edema and a monoventricular left hydrocephaly. The stars indicate the tumor

not only in terms of diagnosis and classification but also in the subsequent management. The radiologic and histopathologic features help differentiate it from the more common ependymoma and astrocytoma $[2,4,9]$.

This case report describes a new case of a young girl with astroblastoma. It discusses clinical, radiologic, pathological, and therapeutic features and the differential diagnosis of this rare neoplasm, with a large review of the literature.

\section{Case presentation}

We report the case of an 8-year-old Moroccan girl who presented with a 1-year history of epileptic seizure, headache, and decreased visual acuity. Cranial magnetic resonance imaging (MRI) revealed a right, occipito-temporal, voluminous, well-demarcated mass with a multicystic component and a characteristic bubbly appearance on T2weighted images and hypointense heterogenous on T1weighted images. After contrast injection, a strong contrast enhancement was observed. There was a peritumoral edema and a monoventricular left hydrocephaly (Fig. 1). MRI findings suggested a diagnosis of a glial neoplasm.

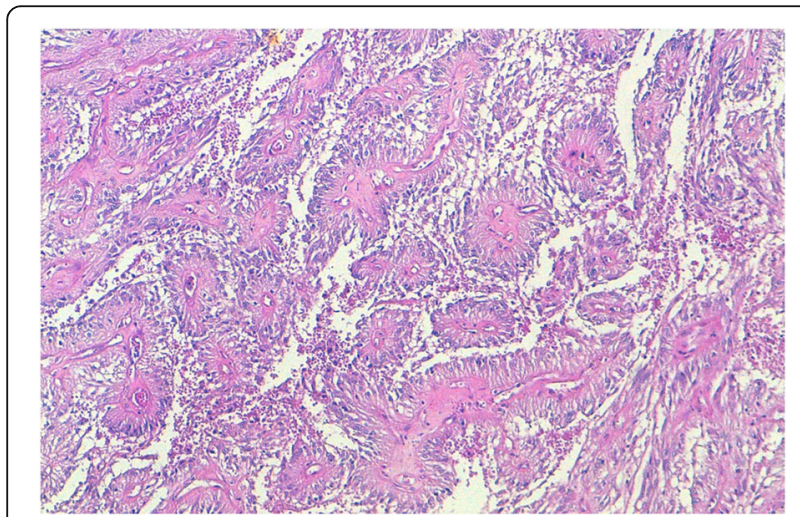

Fig. 2 Microscopic appearance: tumor composed of perivascular rosettes of tumor cells (hematoxylin and eosin stain; original magnification $\times 100$ )
An incomplete (because of the hemorrhage) tumor resection was performed and microscopic examination revealed a tumor composed of perivascular rosettes of tumor cells (Fig. 2). The tumor cells had indistinct cytoplasmic borders. The nuclei were generally round to oval in shape, without nuclear pleomorphism or mitotic activity (Fig. 3). The tumor was very vascular with thickened and focally hyalinized blood vessel walls (Fig. 4). An immunohistochemical analysis showed positive staining for glial fibrillary acid protein (GFAP; Fig. 5). The cells were negative for epithelial membrane antigen (EMA) and Ki-67 labeling index was approximately 7\%. P53 immunostaining was negative. Isocitrate dehydrogenase (IDH) $1 / 2$ gene analysis by polymerase chain reaction (PCR) sequencing did not reveal mutation. Based on these data, the diagnosis of low-grade astroblastoma was confirmed.

\section{Discussion}

Astroblastoma is one of the rarest central nervous system gliomas. It can occur in persons of any age, with a bimodal age distribution, with one peak in infancy (between 5 and

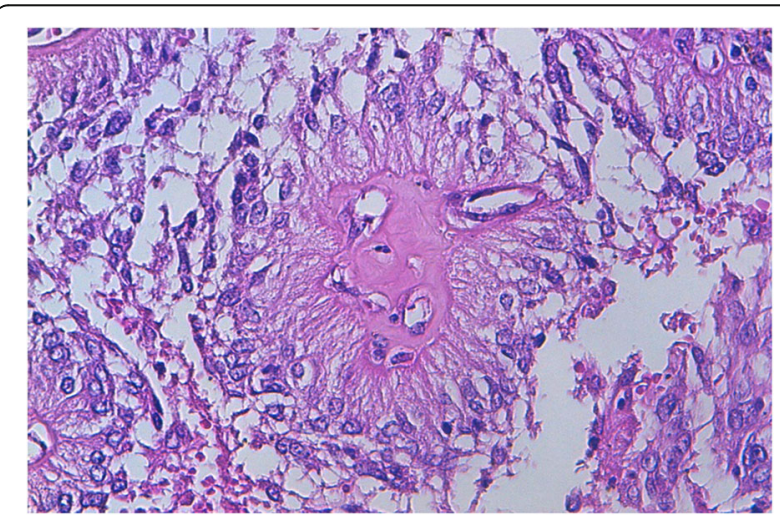

Fig. 3 Microscopic appearance: Tumor cells with indistinct cytoplasmic borders and round to oval nuclei, without nuclear pleomorphism or mitotic activity (hematoxylin and eosin stain; original magnification $\times 400$ ) 


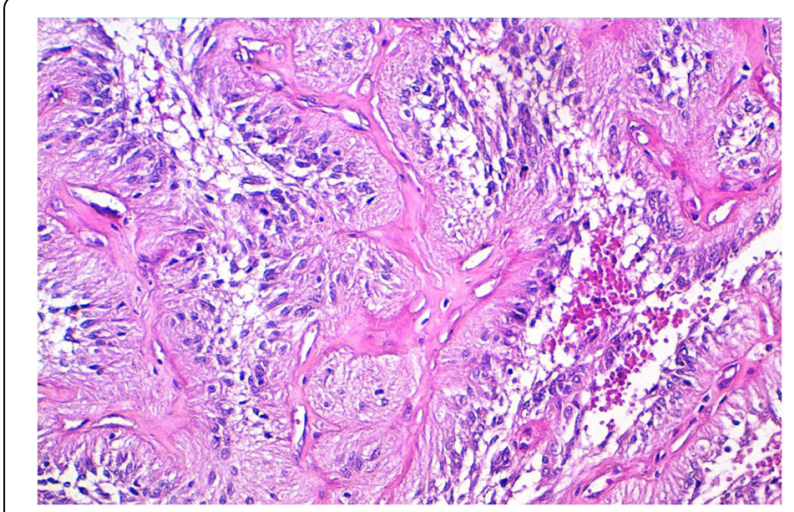

Fig. 4 Microscopic appearance: thickened and focally hyalinized blood vessel walls (hematoxylin and eosin stain; original magnification $\times 100$ )

10 years) and the other one in young adults (between 21 and 30 years). The studies performed to date show a striking female preponderance with a male to female ratio of $1: 11[5-8,18]$.

The tumor usually presents as a well-circumscribed and superficial mass, usually supratentorial with occipital and frontal lobes the most frequently affected sites. However, tumor invasion has also been reported into corpus callosum, cerebellum, brain stem, and optic nerve $[1,2,6,8]$.

Clinical signs and symptoms are dependent on the location and size of the tumor and primarily consist of those associated with elevated intracranial pressure. Headache, seizures, vomiting, and focal neurologic deficits are the most commonly mentioned symptoms $[2,4,7]$.

Considerable confusion has surrounded the diagnosis, the histogenesis, and the classification of astroblastoma. Controversy still exists in the literature of the cell of origin of this neoplasm. Bailey and Bucy [11] believed that astroblastoma originated from astroblasts, an intermediate stage between glioblasts and astrocytes. However,

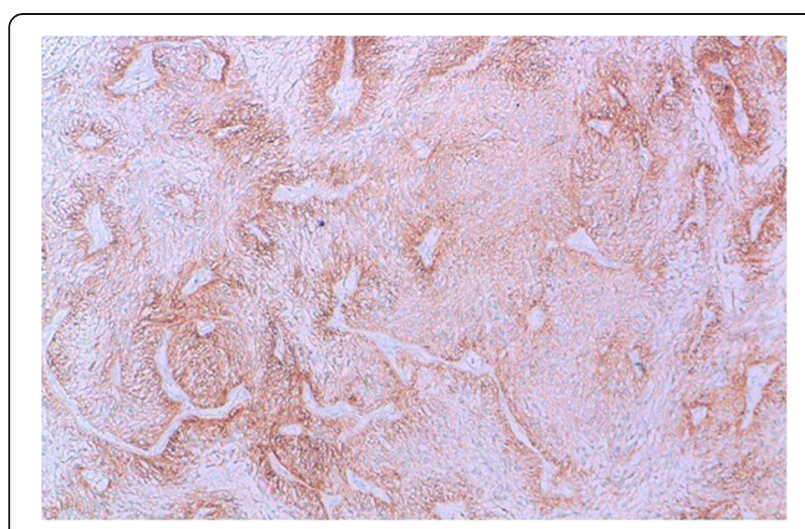

Fig. 5 Positive immunostaining for glial fibrillary acid protein (original magnification $\times 100$ )
Russell and Rubinstein [14] suggested that astroblastomas are dedifferentiated from mature astroglial cells. Later, in a study by Rubinstein and Herman [19], using electron microscopy, it was proven that astroblastomas might originate from persisting groups of embryonic precursor cells, transitional between astrocytes and ependymal cells. Given the lack of consensus, astroblastomas are currently classified as other neuroepithelial tumors by the WHO 2007 [16]; however, lack of sufficient clinicopathological data thwarts the WHO grading of these tumors [6].

On radiographic examination, the lesions show a characteristic appearance that may aid the pathologist in making the diagnosis of astroblastoma. On MRI, it is almost exclusively seen supratentorially and is peripheral in location. It typically appears as a large, well-demarcated, lobulated mass. It often has solid and cystic components with a characteristic bubbly appearance in the solid component, which was believed to result from the tumor vascular architecture, with inhomogeneous contract enhancement and little vasogenic edema $[1,2,4-6,8,9$, 18]. It is hyperintense to white matter on fast fluidattenuated inversion recovery (FLAIR) images and T2weighted images and hypointense to isointense on T1weighted images [1]. Our case showed a typical solidocystic lesion with a bubbly appearance.

On macroscopic examination, astroblastomas were described as superficial, well-demarcated, lobulated, solid, or cystic masses [4].

On histologic examination, an astroblastoma is defined by the presence of perivascular pseudorosettes and prominent perivascular hyalinization. The perivascular pseudorosettes give the characteristic "cartwheel" appearance. They exhibit characteristic epithelioid cells with cytoplasmic processes having blunt-ended foot plates attached to the basal lamina of blood vessels $[2,6,8,9]$. The amount of perivascular hyaline formation varies from case to case; but in the most severe forms, expansive, acellular hyalinized zones will be seen without any residual tumor architecture [9]. Another feature of diagnostic importance is lack of fibrillary background [6]. Astroblastic features must be present in all the tumor extension to make the diagnosis of astroblastoma [8]. This tumor is mostly well circumscribed. Higher grade lesions will occasionally have clusters of tumor cells extending marginally into surrounding brain; however, there are no reports of diffuse infiltration of the surrounding tissue [9]. In our case, prominent hyalinization of the capillary network occurred only focally.

Because astroblastoma exhibits a highly variable biological behavior, a WHO grade has not been established yet. Based on morphology, Bonnin and Rubinstein [20] reported two distinct histological types: prognostically favorable "low-grade/well-differentiated" and unfavorable 
"high-grade/anaplastic" groups. The former includes astroblastomas with uniform perivascular arrangement of pseudorosettes, low to moderate numbers of mitotic figures, minimal cellular atypia, minimal to no vascular endothelial proliferation, and predominant sclerosis of the vascular walls. They are generally indolent and associated with a more favorable prognosis after surgical resections. The latter shows focal or multifocal regions of high cellularity, anaplastic nuclear features, high mitotic rates, vascular proliferation, and necrosis with pseudopalisading. They have shorter postoperative survival times. Our case was considered to be in the low-grade group as it had an orderly growth pattern with no evidence of necrosis, cellular atypia, high mitotic activity, or vascular endothelial proliferation.

Immunohistochemical features of astroblastoma have some variability throughout the literature. Immunostaining for GFAP is positive, lending support to the theory that the tumor cell is derived from an astrocyte cell line. Astroblasts also consistently stain positive with vimentin, suggesting derivation from a more primitive astroblast, and for S-100 protein. Other immunostains, such as neuron-specific enolase (NSE), EMA, cytokeratin (CK), and CAM 5.2, have had highly variable results in the current literature $[2,6,9]$.

Apart from our case, 53 reported cases of astroblastoma are reviewed in this work. Epidemiological, clinical, radiologic, and immunohistochemical characteristics and grading are summarized in Table 1.

The diagnosis of astroblastoma is often difficult. In fact, astroblastic features are not unique to astroblastoma and can also be found in other tumors. Therefore, the combination of the radiologic and the histopathologic characteristics is necessary for making a correct diagnosis. The main differential diagnoses are ependymoma and angiocentric glioma $[4,8,9,18]$. The distinguishing features between astroblastoma and ependymoma are shorter and broader cellular processes and hyalinized or even sclerosed blood vessels $[1,3,8$, 9]. Furthermore, between the pseudorosettes are rarified spaces, in contrast to the compact intravascular architecture of the ependymoma and the lack of fibrillarity in astroblastoma helps to distinguish its pseudorosettes from those found in ependymomas [9]. Ependymomas may show a similar immunohistochemical pattern, but GFAP immunoactivity in ependymomas is often more intense than that in astroblastomas [8]. The distinction with angiocentric glioma is not clear-cut, because this is an ill-defined tumor entity, characterized by perivascular distribution of bipolar and spindle cells, with mild pleomorphism, an infiltrative border, and lack of high-grade features. On immunohistochemical examination, it is typically positive with antibodies to GFAP, S-100 protein, and vimentin. A dot-like pattern of immunoreactivity to
EMA has also been described [18, 21]. Gemistocytic astrocytomas and glioblastomas frequently contain focal areas of perivascular pseudorosettes. Therefore, the diagnosis of astroblastoma should be reserved for welldemarcated gliomas purely or mainly composed of the characteristic gliovascular structure described. The distinction between astroblastomas and nonglial papillary tumors such as papillary meningiomas and metastases from papillary tumors is aided by immunohistochemical features that show positive staining with glial markers such as GFAP and S-100 [8].

Data on the molecular genetics of astroblastoma are rare and only recently available from the literature. A study by Brat et al. [22] demonstrated that astroblastomas have characteristic chromosomal aberrations because they exhibit gain of chromosomes 19 and 20 . These anomalies are different from those of the ependymomas or astrocytic tumors, suggesting that astroblastoma is a distinct entity rather than a variant of ependymoma $[1,4]$. Other alterations noted were losses on $9 q, 10$, and X chromosome [22]. Shuangshoti et al. [23] found loss of heterozygosity at the D19S412 locus on $19 \mathrm{q}$ in a cerebral astroblastoma. More recently, an absence of IDH $1 / 2$ and TP53 mutations, which are known to be involved in the development of low-grade gliomas, was shown in astroblastomas [24, 25]. In this case, there was not IDH1 mutation. P53 immunostaining was negative.

Since astroblastomas are rare and tumor descriptions in the literature concern only individual cases or small collections of cases, optimal treatment protocols have not been established. Total resection is the best treatment. It provides excellent tumor control rates $[1,2]$. Subtotal resection should be avoided, if possible [26]. The addition of adjuvant focal radiotherapy after subtotal resection does not appear to provide equivalent outcomes to gross total resection. Adjuvant therapy for high-grade and recurrent cases is recommended [4, 6 , 26]. Regular follow-up is required even in low-grade variants due to unpredictable behavior. Favorable prognosis is almost invariably associated with well-circumscribed tumors which permit total resection of tumor in all grades [2].

Several investigators have found that astroblastoma prognosis may be predicted by the histology and extent of resection. The low-grade astroblastomas are thought to have a better prognosis than the high-grade ones. Their prognosis is similar to that of low-grade gliomas. High-grade astroblastoma prognosis corresponds to that of anaplastic astrocytomas and has been associated with recurrence and progression [1, 8]. Ahmed et al. [7] presented the largest series of patients with astroblastoma described in the literature $(n=239)$. They found that older age, supratentorial location, and treatment prior to 


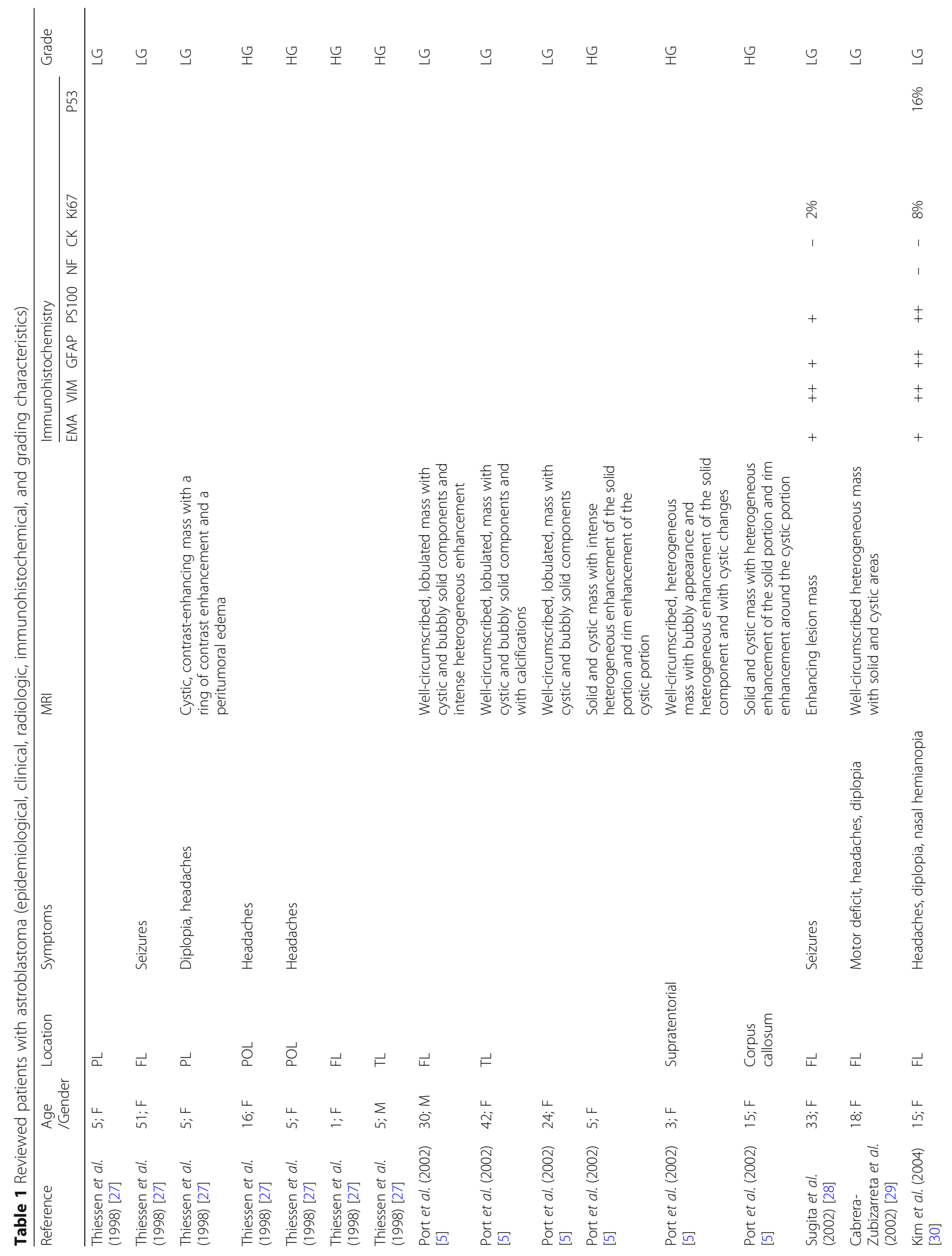




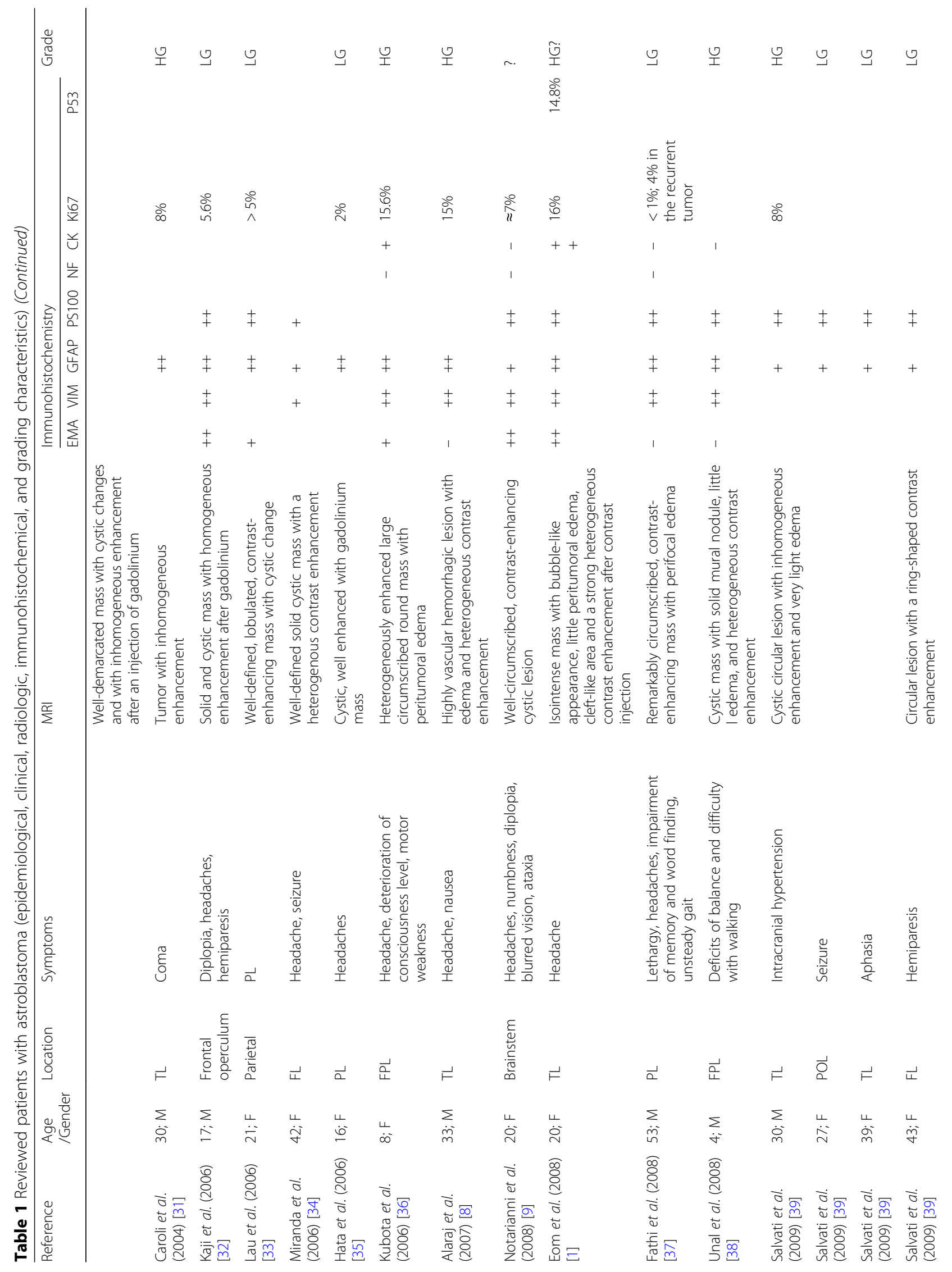




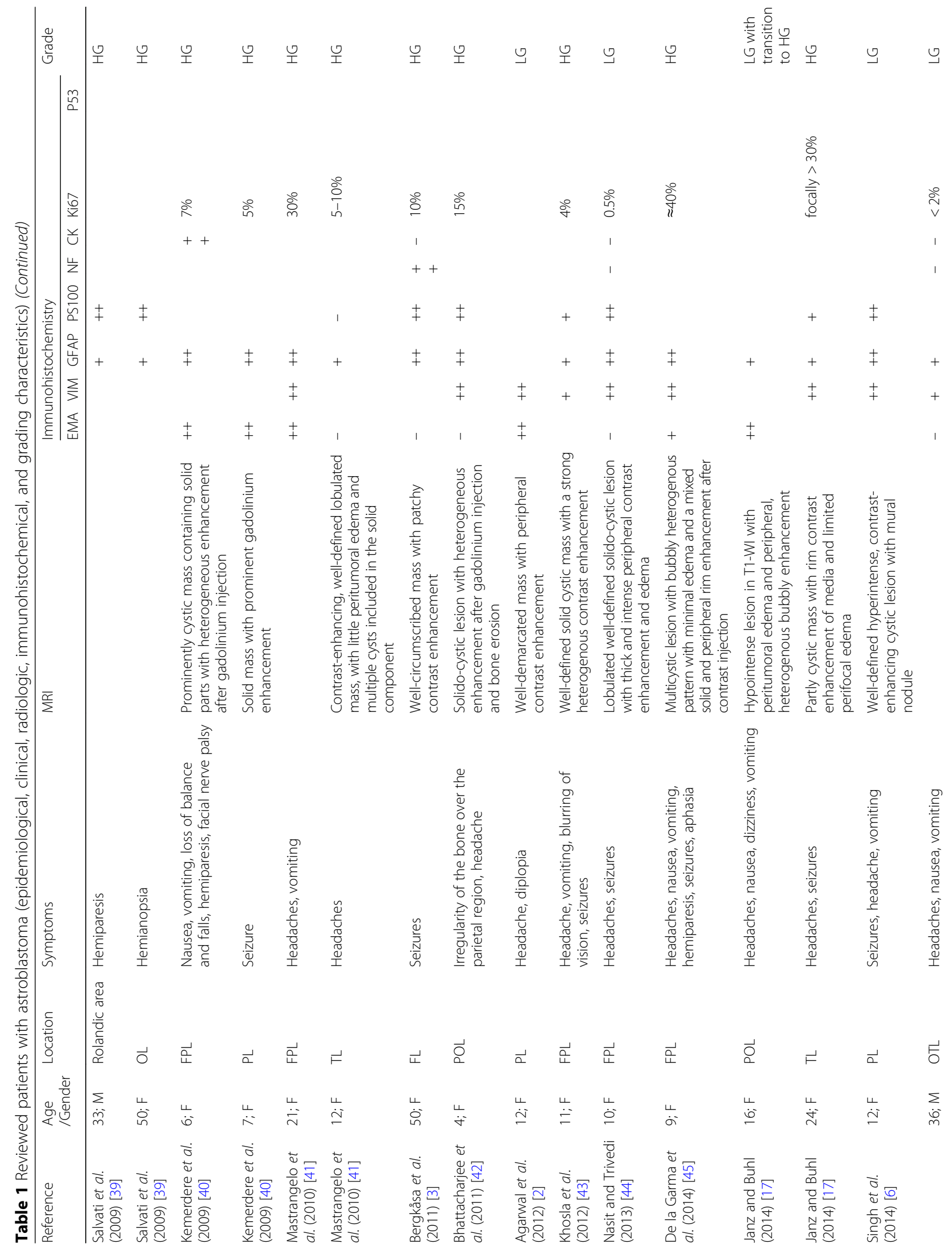




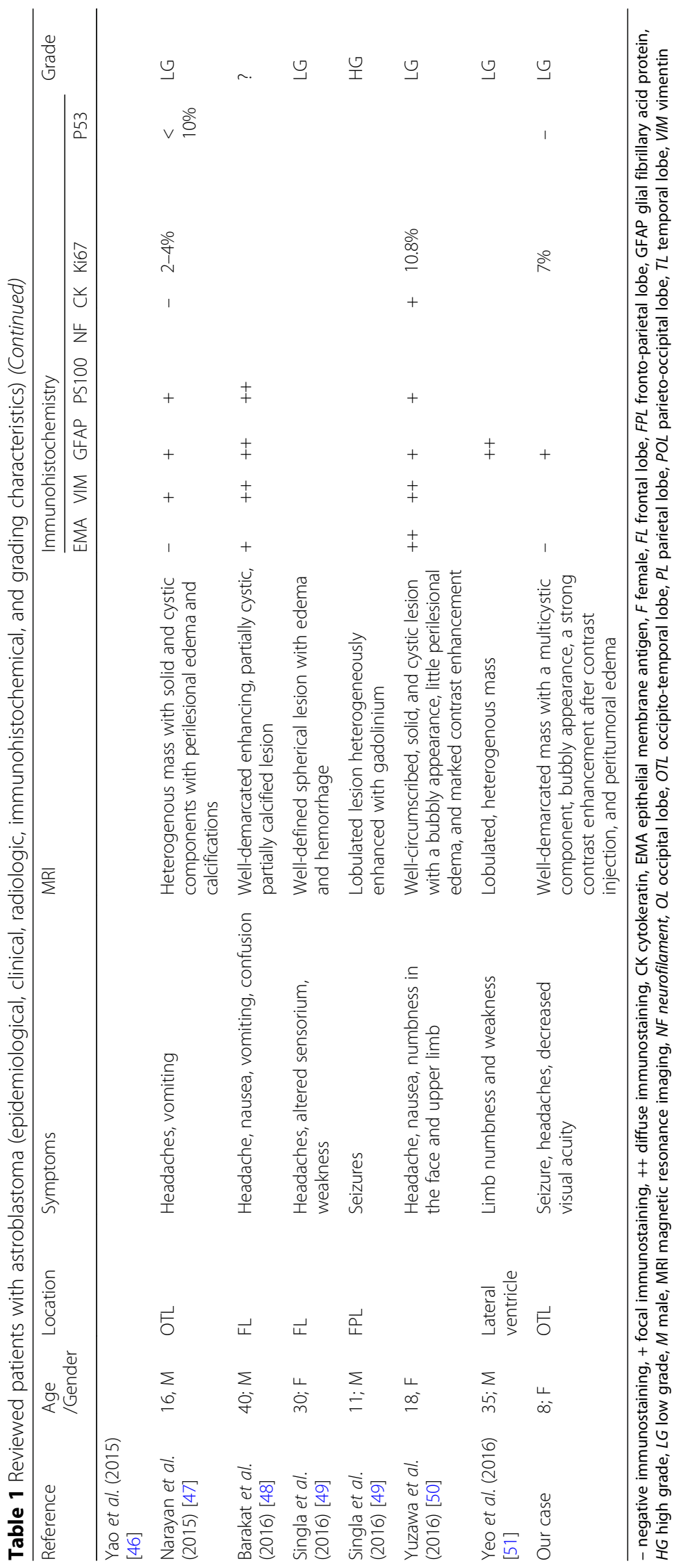


1990 were poor prognostic factors. In addition, they thought the reason why patients with cerebellar tumors had better prognosis was that they might have earlier signs of increased intracranial pressure, leading to a quicker diagnosis and subsequently more timely treatment than their supratentorial counterparts. Similarly, better prognosis for patients diagnosed after 1990 might be related to multiple factors like advances in diagnostics and therapeutic modalities, such as MRI [4].

\section{Conclusions}

Astroblastoma is a very rare primary brain tumor. Its diagnosis is often challenging because of the astroblastic aspects that can be found in astrocytic tumors, in ependymomas, and in non-neuroepithelial tumors. Considerable confusion surrounds its histogenesis and classification. The low incidence rate makes it difficult to conduct studies to examine tumor characteristics.

\section{Abbreviations}

CK: Cytokeratin; EMA: Epithelial membrane antigen; FLAIR: Fluid-attenuated inversion recovery; GFAP: Glial fibrillary acid protein; IDH: Isocitrate dehydrogenase; MRI: Magnetic resonance imaging; NSE: Neuron-specific enolase; PCR: Polymerase chain reaction; WHO: World Health Organization

\section{Acknowledgements}

We thank Prof Afaf Amarti Riffi and Prof Audrey Rousseau who participated in establishing the diagnosis.

\section{Funding}

The authors received no specific funding for this study.

\section{Availability of data and materials}

All data generated or analyzed during this study are included in this published article.

\section{Authors' contributions}

$\mathrm{NH}, \mathrm{HE}$, and $\mathrm{LC}$ performed the histological examination of the tumor and were major contributors to writing the manuscript. NS and SB performed genetic analysis. MYAL performed the radiologic examination. EMC analyzed and interpreted the patient data and performed surgical resection. All authors read and approved the final version of the manuscript.

\section{Ethics approval and consent to participate} Not applicable.

\section{Consent for publication}

Written informed consent was obtained from the patient's legal guardian for publication of this case report and any accompanying images. A copy of the written consent is available for review by the Editor-in-Chief of this journal.

\section{Competing interests}

The authors declare that they have no competing interests.

\section{Publisher's Note}

Springer Nature remains neutral with regard to jurisdictional claims in published maps and institutional affiliations.

\section{Author details}

'Department of Pathology, Hassan II University Hospital, 30000 Fez, Morocco. ${ }^{2}$ Biomedical and Translational Research Laboratory, Faculty of Medicine and Pharmacy, Sidi Mohamed Ben Abdellah University, Fez, Morocco. ${ }^{3}$ Bioactive Molecules Laboratory, Faculty of Science and Technology, Sidi Mohamed Ben Abdellah University, Fez, Morocco. ${ }^{4}$ Department of Radiology, Hassan II University Hospital, Fez, Morocco. ${ }^{5}$ Faculty of Medicine and Pharmacy, Sidi
Mohamed Ben Abdellah University, Fez, Morocco. ${ }^{6}$ Oncogenetic/pathology Unit, Hassan II University Hospital, Fez, Morocco. 'Department of Neurosurgery, Hassan II University Hospital, Fez, Morocco.

Received: 10 July 2017 Accepted: 19 February 2018

Published online: 21 April 2018

\section{References}

1. Eom K-S, Kim JM, Kim T-Y. A Cerebral Astroblastoma Mimicking an Extraaxial Neoplasm. J Korean Neurosurg Soc. 2008;43:205-8.

2. Agarwal V, Mally R, Palande DA, Velho V. Cerebral astroblastoma: A case report and review of literature. Asian J Neurosurg. 2012;7:98-100.

3. Bergkåsa M, Sundstrøm S, Gulati S, Torp SH. Astroblastoma - a case report of a rare neuroepithelial tumor with complete remission after chemotherapy. Clin Neuropathol. 2011;30(6):301-6.

4. Shen F, Chen L-C, Yu Y, Zhou L-F. Astroblastoma: Rare Incidence and Challenges in the Pattern of Care. World Neurosurg. 2014;82(1/2):e125-7.

5. Port JD, Brat DJ, Burger PC, Pomper MG. Astroblastoma: RadiologicPathologic Correlation and Distinction from Ependymoma. Am J Neuroradiol. 2002:23:243-7.

6. Singh DK, Singh N, Singh R, Husain N. Cerebral astroblastoma: A radiopathological diagnosis. J Pediatr Neurosci. 2014;9:45-7.

7. Ahmed KA, Allen PK, Mahajan A, Brown PD, Ghia AJ. Astroblastomas: a surveillance, epidemiology, and end results (SEER)-based patterns of care analysis. World Neurosurg. 2014;82:e291-7.

8. Alaraj A, Chan M, Oh S, Michals E, Valyi-Nagy T, Hersonsky T. Astroblastoma presenting with intracerebral hemorrhage misdiagnosed as dural arteriovenous fistula: review of a rare entity. Surg Neurol. 2007;67:308-13.

9. Notarianni C, Akin M, Fowler M, Nanda A. Brainstem astroblastoma: a case report and review of the literature. Surg Neurol. 2008;69:201-5.

10. Bailey P, Cushing HA. A Classification of Tumors of the Glioma Group on a Histogenetic Basis with a Correlation Study of Prognosis, 83-84. Philadelphia, PA: Lippincott; 1926. p. 133-6.

11. Bailey P, Bucy PC. Astroblastoma of the brain. Acta Psychiatr Neurol. 1930;5:439-61

12. Kernohan JW, Mabon RF, Svien HJ, et al. A simplified classification of the gliomas. Proc Staff Meet Mayo Clin. 1949;24(3):71-5.

13. Zülch KJ. Biologie und Pathologie der Hirn Geschwülste [Biology and pathology of brain tumors]. In: Zülch KJ, Christensen E, editors. Pathologische Anatomie der Raumbeengenden Intrakraniellen Prozesse. Berlin: Springer; 1956. p. 1-702. German.

14. Russell DS, Rubinstein LJ. Pathology of Tumours of the Nervous System. 5th ed. London: Edward Arnold; 1989.

15. Kubota T, Hirano A, Sato K, Yamamoto S. The fine structure of astroblastoma. Cancer. 1985:55(4):745-50.

16. Aldape KD, Rosenblum MK. Astroblastoma. In: Louis DN, Ohgaki H, Wiestler OD, Cavenee WK, editors. World Health Organization Classification of Tumours of the Central Nervous System. Lyon: IARC; 2007. p. 88-9.

17. Janz C, Buhl R. Astroblastoma: Report of two cases with unexpected clinical behavior and review of the literature. Clin Neurol Neurosurg. 2014;125:114-24.

18. Mellai M, Piazzi A, Casalone C, Grifoni S, Melcarne A, Annovazzi L, Cassoni P, Denysenko T, Valentini MC, Cistaro A, Schiffer D. Astroblastoma: beside being a tumor entity, an occasional phenotype of astrocytic gliomas? OncoTargets Therapy. 2015;8:451-60.

19. Rubinstein $\sqcup$, Herman MM. The astroblastoma and its possible cytogenic relationship to the tanycyte. An electron microscopic, immunohistochemical, tissue- and organ-culture study. Acta Neuropathol. 1989;78:472-83.

20. Bonnin JM, Rubinstein LJ. Astroblastomas: a pathological study of 23 tumors, with a postoperative follow-up in 13 patients. Neurosurgery. 1989;25:6-13.

21. Marburger T, Prayson R. Angiocentric Glioma: A Clinicopathologic Review of 5 Tumors With Identification of Associated Cortical Dysplasia. Arch Pathol Lab Med. 2011;135(8):1037-41. 1989.

22. Brat DJ, Hirose Y, Cohen KJ, Feuerstein BG, Burger PC. Astroblastoma: clinicopathologic features and chromosomal abnormalities defined by comparative genomic hybridization. Brain Pathol. 2000;10:342-52.

23. Shuangshoti S, Mitphraphan W, Kanvisetsri S, et al. Astroblastoma: report of a case with microsatellite analysis. Neuropathology. 2000;20:228-32.

24. Camelo-Piragua S, Jansen M, Ganguly A, Kim JC, Cosper AK, Dias-Santagata $D$, Nutt $C L$, lafrate AJ, Louis DN. A sensitive and specific diagnostic panel to distinguish diffuse astrocytoma from astrocytosis: chromosome 7 gain with mutant isocitrate dehydrogenase 1 and p53. J Neuropathol Exp Neurol. 2011;70:110-5. 
25. Fu YJ, Taniguchi Y, Takeuchi S, Shiga A, Okamoto K, Hirato J, Nobusawa S, Nakazato Y, Kakita A, Takahashi H. Cerebral astroblastoma in an adult: an immunohistochemical, ultrastructural and genetic study. Neuropathology. 2013:33:312-9.

26. Sughrue ME, Choi J, Rutkowski MJ, Aranda D, Kane AJ, Barani IJ, Parsa AT. Clinical features and post-surgical outcome of patients with astroblastoma. J Clin Neurosci. 2011;18:750-4.

27. Thiessen B, Finlay J, Kulkarni R, et al. Astroblastoma: does histology predict biological behavior? J Neuro-Oncol. 1998;40:59-65.

28. Sugita $Y$, Terasaki M, Shigemori M, et al. Astroblastoma with unusual signetring-like cell components: a case report and literature review. Neuropathology. 2002;22:200-5.

29. Cabrera-Zubizarreta A, Catón B, Martínez de Guereñu B, et al. Low grade astroblastoma: pathological findings and on magnetic resonance. Rev Neurol. 2002:34:936-9.

30. Kim DS, Park SY, Lee SP. Astroblastoma: A case report. J Korean Med Sci. 2004;19:772-6.

31. Caroli E, Salvati M, Esposiro V, et al. Cerebral astroblastoma. Acta Neurochir 2004;146:629-33.

32. Kaji M, Takeshima $H$, Nakazato $Y$, et al. Low-grade astroblastoma recurring with extensive invasion-case-report. Neurol Med Chir. 2006;46:450-4.

33. Lau PP, Thomas TM, Lui PC, et al. 'Low-grade' astroblastoma with rapid recurrence: a case report. Pathology. 2006;38:78-80.

34. Miranda P, Lobato RD, Cabello A, Gómez PA, Martínez de Aragón A. Complete surgical resection of high-grade astroblastoma with long time survival: case report and review of the literature. Neurocirugia (Astur). 2006;17(1):60-3.

35. Hata N, Shono T, Yoshimoto K, et al. An astroblastoma case associated with loss of hetreozygosty on chromosome 9p. J Neuro-Oncol. 2006;80:69-73.

36. Kubota T, Sato K, Arishima $H$, et al. Astroblastoma: immunohistochemical and ultrastructural study of distinctive epithelial and probable tanycytic differentiation. Neuropathology. 2006;26:72-81.

37. Fathi AR, Novoa E, El-Koussy M, et al. Astroblastoma with rhabdoid features and favorable long-term outcome: report of a case with a 12-year followup. Pathol Res Pract. 2008;204:344-51.

38. Unal E, Koksal Y, Vajtai I, Toy H, Kocaogullar Y, Paksoy Y. Astroblastoma in a child. Childs Nerv Syst. 2008;24:165-8.

39. Salvati $M, D^{\prime}$ Elia $A$, Brogna $C$, et al. Cerebral astroblastoma: analysis of six cases and critical review of treatment options. J Neuro-Oncol. 2009;93:369-78.

40. Kemerdere R, Dashti R, Ulu MO, et al. Supratentorial high grade astroblastoma: report of two cases and review of the literature. Turk Neurosurg. 2009;19:149-53.

41. Mastrangelo $S$, Lauriola $L$, Coccia $P$, et al. Two cases of pediatric high-grade astroblastoma with different clinical behavior. Tumori. 2010;96:160-3.

42. Bhattacharjee S, Pulligopu AK, Uppin MS, et al. Astroblastoma with bone invasion. Asian J Neurosurg. 2011;6:113-5.

43. Khosla D, Yadav BS, Kumar R, Agrawal P, Patel NKFD, Sharma SC. Pediatric Astroblastoma: A Rare Case with a Review of the Literature. Pediatr Neurosurg. 2012;48:122-5.

44. Nasit JG, Trivedi P. Recurrent low-grade astroblastoma with signet ring-like cells and high proliferative index. Fetal Pediatr Pathol. 2013;32:284-92.

45. De la Garma VH, Arcipreste AA, Vazquez FP, Aguilar RR, Castruita UO, Guerra RM. High-grade astroblastoma in a child: Report of one case and review of literature. Surg Neurol Int. 2014;5:111.

46. Yao K, Wu B, Xi M, Duan Z, Wang J, Qi X. Distant dissemination of mixed low-grade astroblastoma-arteriovenous malformation after initial operation: a case report. Int J Clin Exp Pathol. 2015;8(6):7450-6.

47. Narayan S, Kapoor A, Singhal MK, Jakhar SL, Bagri PK, Rajput PS, et al. Astroblastoma of cerebrum: A rare case report and review of literature. J Can Res Ther. 2015;11:667.

48. Barakat MI, Ammar MG, Salama HM, Abuhashem S. Astroblastoma: Case Report and Review of Literature. Turk Neurosurg. 2016:26(5):790-4.

49. Singla N, Dhandapani SS, Kapoor A, Chatterjee D, Vashishta Yeo RK. Hemorrhage in astroblastoma: An unusual manifestation of an extremely rare entity. J Clin Neurosci. 2016;25:147-50.

50. Yuzawa S, Nishihara H, Tanino M, Kimura T, Moriya J, Kamoshima Y, Nagashima K, Tanaka S. A case of cerebral astroblastoma with rhabdoid features: a cytological, histological, and immunohistochemical study. Brain Tumor Pathol. 2016;33(1):63-70.

51. Yeo JJY, Low YYS, Putti TC, Koh KMR. Adult intraventricular astroblastoma. Singap Med J. 2016:57(1):53-4.

\section{Submit your next manuscript to BioMed Central and we will help you at every step:}

- We accept pre-submission inquiries

- Our selector tool helps you to find the most relevant journal

- We provide round the clock customer support

- Convenient online submission

- Thorough peer review

- Inclusion in PubMed and all major indexing services

- Maximum visibility for your research

Submit your manuscript at www.biomedcentral.com/submit
Biomed Central 